\title{
MRI Evaluation of Extra Axial Cerebello Pontine Angle Tumours
}

\author{
Maheswararao Y.V.N ${ }^{1}$, Rama Krishna Rao Baru² \\ ${ }^{1}$ Post graduate, ${ }^{2}$ Professor, Department of Radio-Diagnosis, Narayana Medical College and Hospital, Nellore - 524002 , \\ Andhra Pradesh, India
}

Corresponding author: Dr Ramakrishna B, Department of Radio-Diagnosis, Narayana Medical College and Hospital, Nellore - 524 002, Andhra Pradesh, India

DOI: 10.21276/ijcmsr.2018.3.3.8

How to cite this article: Maheswararao Y.V.N, Rama Krishna Rao Baru. MRI evaluation of extra axial cerebello pontine angle tumours. International Journal of Contemporary Medicine Surgery and Radiology. 2018;3(3):C33C38.

\section{A B S T R A C T}

Introduction: Usually, cerebellopontine angle (CPA) tumors are benign, classified into intra axial, extra axial, extradural and petrous axis tumors. Present study aimed to evaluate the incidence of extra axial cerebellopontine angle tumours and also to characterize extra axial cerebellopontine angle tumours.

Material and Methods: All patients with clinical suspicion of CP angle tumours subjected3T MR imaging system. Special sequences such as DWI and MR spectroscopy was performed.

Results: Extra axial CPA tumours accounts for $7-10 \%$ of brain tumours. Most common extra axial CPA tumour is schwannoma (60\%), followed by meningioma (27\%), epidermoid (7\%), arachnoid cysts (7\%). 51-60 years is the most common age group involved. Schwannomas is common extra axial CPA tumours which are enhancing round masses most commonly arise from the vestibular nerve near the porus acousticus and associated with enlargement of internal auditorycanal. Meningiomas are second most common extra axial CP angle tumours whichoval or hemispheric lesions with a broad attachment to tentorium or petrousdura matter. Epidermoid cysts and arachnoid cysts follows CSF signal intensity on all these quences, epidermoid shows diffusion restriction on DWI but arachnoid cysts not restricted on DWI and completely suppressed on FLAIR.

Conclusion: MRI is the most sensitive noninvasive modality to characterize extra axial CPA tumours. MRI identifies the location and extension of the lesions based on their characteristic signal and enhancement pattern on contrast.

Key words: Cerebellopontine Angle Tumor, Schwannoma, Meningiomas

\section{INTRODUCTION}

The cerebellopontine angle (CPA) cistern is a subarachnoid space containing cranial nerves and vessels bathed in cerebrospinal fluid (CSF). The CPA is bounded by the pons, the anterior aspect of the cerebellum and the petrous temporal bone covered by dura mater. It is centred by the internal auditory canal (IAC) and extends caudally from the Vth cranial nerve to the IX-X-XIth cranial nerve complex. Tumours of the cerebellopontine angle (CPA) comprise 10\% of all intracranial tumours ${ }^{1,2}$.

Vestibular schwannomas account for $70 \%-80 \%$ of all CPA lesions, meningiomas $5-12 \%$ and epidermoid cysts $2-6 \%$, other lesions, which accounts each $\leq 1 \% \%^{1,2,3}$. Tumours derive from various anatomical structures, includes primary origin from internal auditory meatus, pontocerebellar cistern and lateral recess of the $4^{\text {th }}$ ventricle, temporal bone, brain stem, or cerebellar nervous tissue $\mathrm{e}^{4,5,6}$.

CPA tumours, although uniform in location, are diverse pathologically and present clinically depending upon the site of tumour origin and displacement of the neurovascular structures. Clinical presentation of the CPA tumours is variable and it depends upon the size and location of the tumour. It can be asymptomatic in early stage or it can give vertigo, tinnitus, or hearing loss. Vascular compression of the vestibule cochlear nerve also causes vertigo and tinnitus. Computerized tomography (CT) and magnetic resonance imaging (MRI) are the primary modalities for diagnosis of cerebellopotine lesions. MRI is considered superior in differentiating the different types of CPA masses. The MR imaging technique described is simple and non-invasive. The high contrast resolution and multiplanar capabilities of MR helps to delineate shape and margins, extent, mass effect, intensity at MR imaging, enhancement and adjacent bone reaction. The main radiological diagnostic goal is the description of the relation of the tumour to IAM, the brain stem and cerebellar hemispheres. The second line basic information is if the lesion is extra or intracerebral.

In addition to the computed tomography (CT) and conventional magnetic resonance (MR) imaging characteristics of the different CPA lesions (including anatomic site of origin, shape, density, signal and behaviour after contrast media injection), MR advanced techniques such as diffusion-weighted imaging (DWI) and perfusion imaging, as well as MR spectroscopy, when available, as they may bring crucial new data that allow accurate preoperative diagnosis. The aim of the study was to evaluate the incidence of extra axial cerebellopontine angle tumours and also to characterize extra axial cerebellopontine angle tumours. 


\section{MATERIAL AND METHODS}

Patients attending the department of Radio-diagnosis, Narayana Medical College, Nellore was the main source of data for this study. The study was approved by the institutional ethical committee and guidelines of the committee were followed in the study. The study was explained to all the cases or relatives and consent was obtained. All patients referred to the department of Radiology with clinical suspicion of CPA tumours for the duration of 2 years from 2015 to 2017 September subjected for study.

Inclusion Criteria: All Patients from all age groups who are clinically suspected to have ICSOL. Patients without a clinical suspicion but showing an cp angle lesion/ ICSOL on CT scan.

Exclusion Criteria: Patient having history of claustrophobia. Patient having history of metallic implants insertion, cardiac pacemakers. Metallic foreign body in situ. Patient clinically unstable.Trauma. Infectious pathology. Those with intra axial tumors within the brain.

EQUIPMENT: The MR examinations were performed on all patients who met inclusion criteria at a $3 \mathrm{~T}$ wholebody MR system (DISCOVERY 750W 3T MRI GE Healthcare,Chicago, Illinois) using a 32-channel phased array head coil. Conventional spin echo sequences, Axial T1, T2, Coronal FLAIR, Sag T2, FSPGR, and Post-contrast $\mathrm{T} 1+\mathrm{C}$.Special sequences such as DWI and MR spectroscopy was performed as and when required.

\section{STATISTICAL ANALYSIS}

Statistical analysis performed by SPSS (Version 10.0) software. Incidence was expressed in percentage and proportion in total study population. Mean value used to express the presenting symptoms and disease characteristic features. Microsoft Excel was used to analyse the statistics.

\section{RESULTS}

Thirty patients were evaluated, whose age group ranged from 10 to 90 years. The highest incidence of extra axial cp angle tumours were found in 51-60 years age group accounting for $29 \%$ of cases and least was seen in age group of 11-20 years constituting 4\%.Thirty patients were evaluated of which 9 (30\%) were males and 21 (70\%) were females.Out of the 30 patients who were evaluated, schwannoma (60\%) is the most common pathology followed by meningioma (26.7\%), epidermoid (6.7\%), arachnoid cysts(6.7\%). The most common extra axial CP angle tumour is schwannoma with 18 cases $(60 \%)$. This was followed by meningioma with 8 cases $(26.7 \%)$, followed by epidermoid and arachnoid cysts with 2 cases each (6.7\%). Extra axial $\mathrm{CP}$ angle tumors are more common above $4^{\text {th }}$ to $5^{\text {th }}$ decade.Peak age incidence noted in $5^{\text {th }}$ to $6^{\text {th }}$ decade with 8 cases $(26.7 \%)$.

Out of 18 cases of Schwannoma 4 cases in $5^{\text {th }}$ to $6^{\text {th }}$ decade followed by 3 cases each in $4^{\text {th }}, 6^{\text {th }}$ and $7^{\text {th }}$ decades. Out of 8 cases Meninigioma 3 cases in $5^{\text {th }}$ to $6^{\text {th }}$ decade. Out of 30 cases of extra axial CPA tumours 21 cases are female (70\%), males 9 cases $(30 \%)$ with female preponderance, female:male ratio being 2.3:1 (Table 1 ).

Out of 18 cases of Schwannoma 12 cases of females, 6 cases of males, out of 8 cases of Meningioma 6 cases of females, 2 cases of males, 2 cases of arachnoid cysts of females, 1 case of epidermoid cyst is male and another case is female. So, there is female preponderance in extra axial CPA tumours.

Majority of the patients shows headache and dizziness. Majority of the Schwannoma patients shows hearing loss, headache, tinnitus and dizziness (Table 2).

Out of 18 cases of Schwannoma 7 case shows homogenous enhancement (39\%), 11 cases shows heterogenous enhancement (61\%) on contrast. Out of 8 cases of Meningioma 7 case shows homogenous enhancement (87\%), 1 case shows heterogenous enhancement (13\%) on contrast. Out of 2 cases of each arachnoid cyst and epidermoid cyst follows CSF signal intensity on T1, T2 and FLAIR (Figure 1 and Figure 2). Diffusion restriction in 2 cases (100\%) of epidermoid cyst, no restriction in 2 cases of arachnoid cysts.

\section{DISCUSSION}

In our study of MR imaging of extra axial $\mathrm{cp}$ angle tumors, we evaluated 30cases. Out of Thirty patients evaluated schwannoma diagnosed in 18 cases (60\%).Among the 18 cases, Males were 6 and Females were12 with female to male ratio 2.3:1. Maximum number of patients in the age

\begin{tabular}{|l|c|c|c|c|c|c|c|c|c|}
\hline Tumor type & $\mathbf{1 0 - 2 0}$ & $\mathbf{2 1 - 3 0}$ & $\mathbf{3 1 - 4 0}$ & $\mathbf{4 1 - 5 0}$ & $\mathbf{5 1 - 6 0}$ & $\mathbf{6 1 - 7 0}$ & $\mathbf{7 1 - 8 0}$ & $\mathbf{8 1 - 9 0}$ & Total \\
\hline Schwannoma & 1 & 2 & 2 & 3 & 4 & 3 & 3 & 0 & 18 \\
\hline Meningioma & 0 & 0 & 1 & 1 & 3 & 1 & 1 & 1 & 8 \\
\hline Arachnoid cyst & 0 & 1 & 1 & 0 & 0 & 0 & 0 & 0 & 2 \\
\hline Epidermoid cyst & 0 & 0 & 1 & 0 & 0 & 1 & 0 & 0 & 2 \\
\hline Total & 1 & 3 & 5 & 4 & 7 & 5 & 4 & 1 & 30 \\
\hline \multicolumn{8}{|c|}{ Table-1: Age incidence orious extra axial CP angle tumors $(\mathrm{n}=30)}$. \\
\hline
\end{tabular}

\begin{tabular}{|l|c|c|c|c|}
\hline Symptoms & Schwannoma $\mathbf{( n = 1 8 )}$ & Meningioma $\mathbf{( n = 8 )}$ & Arachnoid $\mathbf{n}=\mathbf{2})$ & Epidermoid $\mathbf{( n = 2 )}$ \\
\hline Hearing loss & 14 & 3 & 0 & 0 \\
\hline Tinnitus & 7 & 2 & 1 & 1 \\
\hline Headache & 10 & 3 & 2 & 2 \\
\hline Dizziness & 6 & 1 & 2 & 0 \\
\hline Facial numbness & 2 & 0 & 0 & 0 \\
\hline Diplopia & 1 & 0 & 0 \\
\hline \multicolumn{7}{|l|}{ Table-2: Presenting symptoms and number of patients. } \\
\hline
\end{tabular}



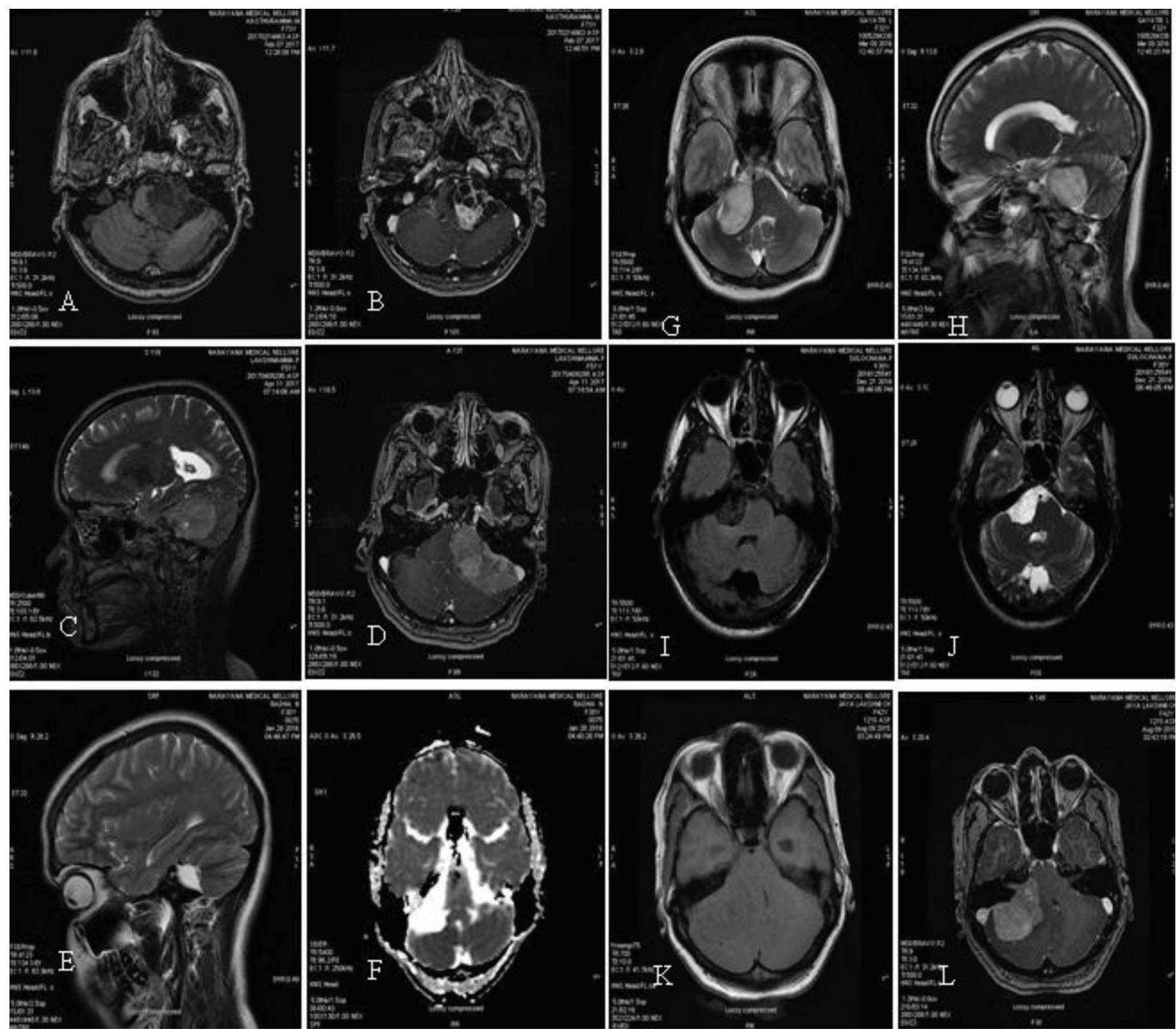

Figure-1:A,B. Large extra axial left CP angle mass with cystic components with peritumoral arachnoid cyst.(Cystic Acoustic Schwannoma). B, C. Extra axial left tentorial meningioma showing heterogenous enhancement on contrast(Meningioma). D,E. Arachnoid cyst in right CP angle flowing CSF signal intensity on T1 and T2 with suppression on FLAIR and no diffusion restriction on DWI (Arachnoid Cyst). G, H. Extra axial right CP angle mass encasing facial,vestibular and cochlear nerve roots.(Acoustic Schwannoma). I,J. Epidermoid cyst in right CP angle showing minimal suppression on FLAIR with diffusion restriction on DWI. K,L.Large well defined lobulated homogenously enhancing extra axial T1 isointense and T2 hyperintense mass in the right $\mathrm{CP}$ angle with broad base towards the tentorium.

group of $50-60 \mathrm{yrs}$ constituting $40 \%$ of patients. Unilateral involvement is seen in 17 cases and bilateral involvement is noted in 1 case, which is a case of Neurofibromatosis type II with multiple vestibular schwannoma in cp angle, meckel's cave, lateral walls of cavernous sinuses and Neurofibromas in spinal canal. The common involved location is vestibular component of VIII nerve, then facial and trigeminal nerves. In this study, 17 cases of vestibular schwannoma (89.4\%) and 1 case of trigeminal schwannoma were recorded.

Previous studies reported that schwannomas arise from the vestibulocochlear nerve, is more often than the other cranial nerve and the vestibular division is more commonly involved than the cochlear division ${ }^{7,8}$.

Literature reported that vestibular schwannomas accounts 8 to $10 \%$ and $60-90 \%$ of total CPA tumors ${ }^{9,10}$. In the current study, the common lesion observed was vestibular schwannoma, accounts $53.3 \%$ in total, which was consistent with the previous studies.

In the present study most of the vestibular schwannoma's were hypointense relative to pons on T1-weighted images and hyperintense to pons on T2-weighted images.Press GA, Hesselink JR ${ }^{11}$, Tali ET et al ${ }^{12}$, Valvassori GE et $\mathrm{al}^{13}$, and Daniels DL et $\mathrm{al}^{14}$, reported that on T1-weighted images, schwannomas are usually isointense or mildly hypointense relative to the pons and are hyperintense to cerebrospinal fluid CSF. On T2 weighted images they shows mild hyperintense to pons and isointense to hypointense to CSF. By MR imaging, various stages in intratumoral haemorrhage may also be detected ${ }^{15}$.

Curati WL et al, ${ }^{16}$ demonstrated that vestibular schwannomas 

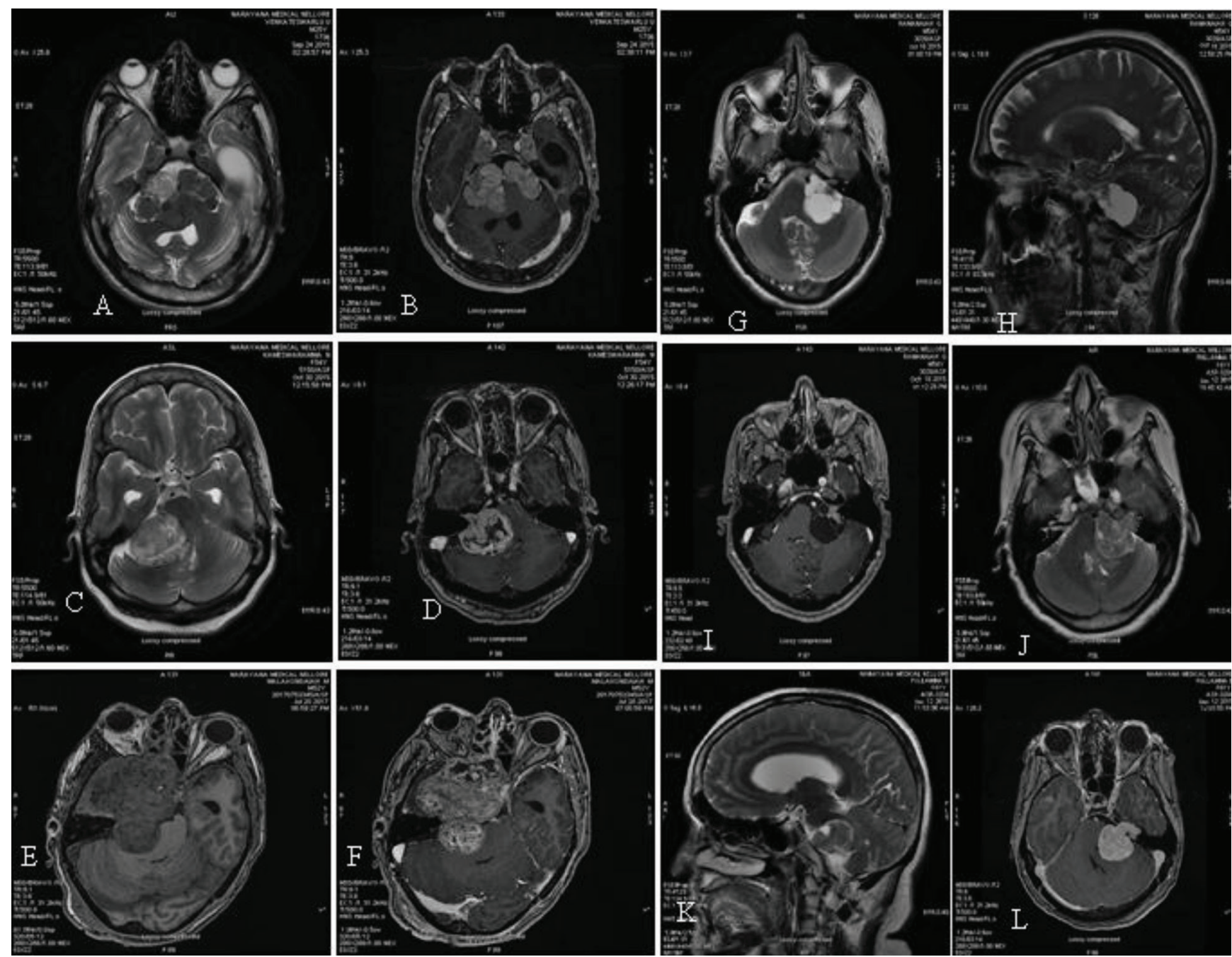

Figure-2: A,B. Multiple extra axial, well defined, lobulated, T1 iso and T2 hyperintense masses in bilateral CP angles with good heterogenous enhancement on contrast similar type of lesion in bilateral meckels cave (Bilateral Vestibular Schwannomas in Neurofibronatosis-II). C.D. Well defined extra axial right CP angle mass isointense on T1 and hyperintense on T2 with significant peripheral enhancement with few non enhancing central areas. E,F. Trigeminal Schwannoma. G,H,I. Well defined T1 hypointense and T2 hyperintense, predominantly cystic lesion with few solid components in left $\mathrm{CP}$ angle with heterogenous enhancement.J,K,L. FSPGR BRAVO CONTRAST. Well defined T1 hypointense and T2 hyperintense lesion with heterogenous enhancement in left $\mathrm{CP}$ angle involving IAC

enhance intensely after contrast on T1-weighted images. The sensitivity of the contrast enhanced, T1-weighted, MR imaging may approach $100 \%$ in identifying schwannomas, with small voxel size ${ }^{17}$. In the present study, all of the cases with vestibular schwannoma showed marked to moderate enhancement after administration of gadolinum and most of the cases showed homogenous enhancement which was consistent with the above study.

Breger RK et $\mathrm{al}^{18}{ }^{18}$ found that vestibular schwannomas may enhance substantially more than meningiomas, neurofibromas and paragangliomas on contrast enhanced T1 imaging. However, enhancement varies greatly within tumours of the same type and overlaps between different tumour types. Similar results were seen in the present study. Vestibular schwannoma epicentered upon internal auditory canal and extended within the canal in ten out of seventeen lesions in the present study. This agrees with Mulkens et $\mathrm{al}^{19}$ study on MR findings in diagnosis of acousticschwannoma. Vestibular schwannomas do not extend anterosuperiorly above the dorsum, and extreme rarely herniate into the middle cranial fossa. None of the vestibular schwannomas in the present study extended into the middle cranial fossa. The findings of the present study were consistent with the literature described.

Hodgson TJ et al, ${ }^{20}$ reported that signal intensity of the masses on MRI will not contribute to the accurate radiographic diagnosis of the intracanalicular meningioma. They will also both brightly enhance after administration of contrast medium. Although it is very difficult to differentiate a meningioma from a vestibular schwannoma if an entirely intracanalicular type is encountered, other extension patterns may provide some information leading to the correct diagnosis.

One case of trigeminal schwannoma encountered in this study. On clinical examination there was involvement of the cranial nerve $\mathrm{V}$ which was also seen in the study done by Bartels LJ and Arrington $\mathrm{JR}^{10}$ who reported that trigeminal nerve schwannomas tend to involve the ganglion, the nerve 
root, or both. Therefore symptoms of cranial nerve $\mathrm{V}$ tend to dominate over dysfunction of cranial nerve VIII and the patients present with facial pain or numbness.

In the present study, one lesion was showed both solid and cystic components. Both the lesions showed marked enhancement on post contrast sequences. Similar findings were described by Valavanis $A$ et $\mathrm{al}^{9}$ and Goldberg $\mathrm{R}$ et $\mathrm{al}^{21}$. On T1, most tumors are isointense to the cortical grey matter (from 56\% to 94\%). Hypointense meningiomas account from $20 \%$ to $48 \%$, and hyperintense tumors on T1weighted images are rare. On T2-weighted images, about $50 \%$ of the tumors remain isointense with the brain cortex. Hypointense tumors are less common, from $4 \%$ to $18 \%$, whereas hyperintense lesions account for $35 \%$ to $44 \% 22,23$.

In the present series, on T1-weighted images, Out of 8 cases of Meningioma 5caseswereIso-intense (62.5\%), 2 cases hypo-intense (25\%),1 caseshowmixedintensity (12.5\%). On the T2-weighted images, Out of 8 cases of Meningioma in 6 cases were hyperintense (75\%), 1 case was iso intense (12.5\%) 1 case show mixed intensity (12,5\%) to the cortical grey matter.

In our study, all the meningiomas showed enhancement after contrast administration, Out of 8 cases of Meningioma 7 case shows homogenous enhancement (87\%), 1 case shows heterogenous enhancement (13\%) on contrast.

Cystic foci, haemorrhage and calcifications may be seen in approximately $20 \%$ of the patients with meningiomas ${ }^{22}$. In the present study, cystic components and foci of calcification and haemorrhage were seen in $25 \%, 12.5 \%$ and $12.5 \%$ of the patients, respectively. The presence of brain edema is frequently reported in patients with meningiomas ${ }^{22,24,25}$. Several studies tried to elucidate the tumour characteristics associated with the presence of edema. The tumour size,location, signal intensity on T2-weighted images and invasive pattern of brain-tumour interface were related to the presence of edema in patients with meningiomas. However, the histological subtypes were not related with this finding ${ }^{24,25}$. In the present study, $62.5 \%$ of the patients showed brain edema, which more commonly was discrete (50\%).

Nakau et al., ${ }^{26}$ studied the correlation of the MR imaging and histopathological findings in nine cases of meningiomas with dural tail sign. They suggestedthattumourcellnestsinth edura-materofthosepatients, making the surgical resection of these areas mandatory. Almost $35 \%$ of the patients with meningiomas may present the dural tail signal on postcontrast T1-weighted images ${ }^{22}$. In the present series this sign was seen frequently, being identified in $50 \%$ of the patients. MRI is the definitive diagnostic tool for evaluation of arachnoid cysts as it confirms the extra-axial location and shows homogenous T2 weighted signal hyper intensity within the cyst similar to that of CSF. Fluid attenuated inversion recovery sequences (FLAIR) are also useful to confirm the similarity of the cyst fluid to $\mathrm{CSF}^{27,28}$.

Eslick et al., reported a patient with an arachnoid cyst of the cerebellopontine angle that caused diplopia via direct compression of cranial nerve $\mathrm{VI}^{29}$. Arachnoid cysts may also become symptomatic by compressing the brainstem ${ }^{30}$.

MRI is helpful in differentiating arachnoid cysts from those cystic lesions. If a pathologic cause of a retrocochlear disorder is suspected in a patientwith a unilateral sensorineural hearing loss and tinnitus, MRI should be performed to evaluate the cerebellopontine angle.

In our present study we evaluated 2 cases of arachnoid cysts. Both cases are females, In both cases there is involvement on right side as arachnoid cyst more common on right side. Epidermoid tumours represent 0.2 to $1.4 \%$ of all primary intracranial tumors. CPA epidermoids constitute $40 \%$ of all intracranial epidermoids and the incidence of epidermoids among all CPA tumors is approximately $5 \%$.

In our study, a CISS image is the best sequence for detecting epidermoids. Although most epidermoid tumors are slightly hyperintense relative to CSF on T1-weighted image, CISS sequences demonstrate these lesions more clearly. Because a CISS sequence provides high spatial resolution with very thin section, it is possible to detect the exact tumour extension, even for a small lesion in Meckel's cave.

In our present study we evaluated 2 cases of epidermoid cysts, one case is male and another is female. Follow the CSF signal intensity on T1 and T2W imaging and minimal suppression on FLAIR, but showing diffusion restriction on DWI in both the cases.

\section{CONCLUSION}

A spectrum of usual and unusual lesions exists in the $\mathrm{CP}$ angle. Amongextra axial $\mathrm{CP}$ angle tumours acoustic schwannomas are most common tumours at $\mathrm{CP}$ angle followed by meningiomas.Signal intensity on MR imaging, enhancement, shape and margins, extent, mass effect and adjacent bone reaction are also helpful in establishing diagnosis.MRI is the most sensitive non-invasive modality in the characterization of extra axial cp angle tumours.It can identify the site and extension of the lesions as well as the characteristic signal and enhancement pattern on contrast. Apart from diagnosing, MR imaging plays an important role in stratifying patients into appropriate treatment options.

\section{REFERENCES}

1. Moffat DA, Ballagh RH. Rare tumours of the cerebellopontine angle. Clin Oncol (R Coll Radiol) 1995;7(1):28-41.

2. Brunori A, Scarano P, Chiappetta F. Non-acoustic neuroma tumor (NANT) of the cerebello-pontine angle: A 15-year experience. J Neurosurg Sci 1997;41 (3):159-68.

3. Bonneville F, Sarrazin JL, Dupuch KM, Iffenecker C, Cordoliani YS, Doyon D, Bonneville JF. Unusual Lesions of the Cerebellopontine Angle: A Segmental Approach. Radiographics 2001;21 (5):419-38.

4. Schaller B. Cerebellopontine angle surgery. Part 1: General remarks. HNO 2003;51 (6):284-95.

5. Brackmann DE, Kwartler JA. A review of acoustic tumors: 1983-1988. Am J Otol 1990; 11 (2):216-32.

6. Smirniotopoulos JG, Yue NC, Rushing EJ. Cerebellopontine angle masses: Radiologic-pathologic correlation. Radiographics 1993;13 (4):1131-47.

7. Clemis JD, Ballad WJ, Baggot PJ, Lyon ST. Relative frequency of inferior vestibular schwannoma. Arch Otolaryngol Head Neck Surg. 1986;112(2):190- 194.

8. Komatsuzaki A,Tsunoda A. Nerve origin of the acoustic 
neuroma. J Laryngol Otol. 2001;115(5):376-379.

9. Valavanis A, Schubiger O, Naidich T. Clinical imaging of the cerebellopontine angle. Berlin: SpringerVerlag;1987.

10. Bartels LJ, Arrington JR. Rare tumors of the cerebellopontine angle. In: Jackler RK, Brackmann D, editors.Neurotology. St. Louis: Mosby; 1994. pp. 835861.

11. Press GA,HesselinkJR.MR imaging of cerebellopontine angle and internal auditory canal lesions at 1.5 T.AJR. 1988;150(6):1371-1381.

12. Tali ET, Yuh WT, Nguyen HD, et al. Cystic acoustic schwannomas: MR characteristics. AJNR.1993;14(5):1241-1247.

13. Valvassori GE, Garcia Morales F, Palacios E, Dobben GE. MR of the normal and abnormal internal auditory canal. AJNR.1988;9(1):115-119.

14. Daniels DL, Millen SJ, Meyer GA, et al. MR detection of tumor in the internal auditory canal. AJR.1987;148(6):1219-1222.

15. Gomori JM, Grossman RI, Goldberg HI, et al. Intracranial hematomas: imaging by high-field MR. Radiology.1985;157(1):87-93.

16. Curati WL, Graif M, Kingsley DP, et al. Acoustic neuromas: Gd-DTPA enhancement in MR imaging. Radiology. 1986;158(2):447-451.

17. Held P,Fellner C, Seitz J, et al. The value of T2-weighted MR images for the diagnosis of acoustic neuromas.Eur J Radiol. 1999;30(3):237-244.

18. Breger RK, Papke RA, Pojunas KW, et al. Benign extraaxial tumors: contrast enhancement with GdDTPA.Radiology. 1987;163(2):427-429.

19. Mulkens TH, Parizel PM, Martin JJ, et al. Acoustic schwannoma: MR findings in 84 tumors. AJR.1993;160:395-398.

20. Hodgson TJ, Kingsley DP. Meningioma presenting as a mass in the internal auditory canal. Neuroradiology. 1995;37:479-480.

21. Goldberg R, Byrd S, Winter J, et al. Varied appearance of trigeminal neuroma on CT. AJR. 1980;134(1):57-60.

22. Atlas SW.Magnetic resonance imaging of the brain and spine. Philadelphia: Lippincott Willians and Wilkins, 2002.

23. Maiuri F, Iaconetta G, de Divitiis O, Cirillo S, Di Salle F, De Caro ML. Intracranial meningiomas: correlations between MR imaging and histology. Eur J Radiol1999;31 (1):69-75.

24. Souto AA, Chimelli L, Takya CM, Souza JM, Fonseca AL, Silva LF. Brain edema in meningiomas: radiological and histological factors. Arq Neuropsiquiatr2002;60 (5):807-817.

25. Nakano $T$, Asano $K$, Miura $H$, Itoh $S$, Suzuki S. Meningiomas with brain edema: radiological characteristics on MRI and review of the literature. Clin Imaging 2002;26 (3):243-249.

26. Nakau H, Miyazawa T, Tamai S, et al. Pathologic significance of meningeal enhancement ("flare sign") of meningiomas on MRI. Surg Neurol 1997;48 (4):584590.

27. Brackmann DE, Arriaga MA: Extra-axial neoplasms of the posterior fossa. In: Cummings CW, Fredrickson
JM, Harker LA, Krause CJ, Richardson MA, Schuller DE (eds) Otolaryngology Head and Neck Surgery. 3rd ed. St. Louis, MO: Mosby-Year Book: 1998:3294-3314.

28. Ottaviani F, Neglia CB, Scotti A, Capaccio P: Arachnoid cyst of the cranial posterior fossa causing sensorineural hearing loss and tinnitus: a case report. Eur Arch Otorhinolaryngol 2002; 259 (2):306-308.

29. Eslick GD, Chalasani V, Seex K: Diplopia and headaches associated with cerebellopontine angle arachnoid cyst. ANZ J Surg 2002; 72 (1):915-917.

30. Greenberg MS: Primary brain tumors. Handbook of Neurosurgery. 6thedition.NewYork, Thieme 2006: 408479 .

\section{Source of Support: Nil; Conflict of Interest: None}

Submitted: 25-06-2018; Accepted: 26-07-2018; Published online: 07-08-2018 